\title{
¿Patriotas contra realistas?: Participación y experiencias de los sectores populares durante la guerra en el espacio sur-andino, 1809-1825
}

\section{Patriots against royalists?: Participation and experiences of the popular sectors during the war in the south Andean space, 1809-1825}

Marisa Davio ${ }^{1}$

\section{Resumen}

El objetivo de este artículo es el análisis de la participación y movilización de los sectores populares, que en su amplia mayoría integraron las tropas tanto patriotas o realistas en la guerra revolucionaria dentro del espacio sur-andino. A partir del estudio de diferentes casos, se intenta comprender las experiencias de la guerra y durante este proceso que derivaría en la independencia de los países de América del Sur. Por tal motivo, se cuestiona la razón por la cual luchaban los integrantes de ambas tropas de los ejércitos o de las milicias convocadas, los conceptos políticos que utilizaron en sus discursos para identificarse con la lucha a favor de una causa determinada y las retribuciones solicitadas para permanecer en los cuerpos militares.

1 Investigadora adjunta del Instituto Superior de Estudios Sociales, CONICET, Tucumán.

Correspondencia (Corresponding author): mari.davio@gmail.com; Código ORCID: 0000-0002-2942-1680. 
¿Patriotas contra realistas?: Participación y experiencias de los sectores populares durante la guerra en el espacio sur-andino, 1809-1825

Palabras clave: Guerra de la Independencia, sectores populares, patriotas, ejército realista, área sur-andina

\section{Abstract}

The objective of this article is to analyze the participation and mobilization of the popular sectors, the vast majority of which were part of both patriotic and royalist troops in the revolutionary war within the southern-Andean space. From the study of different cases, the aim is to understand the experiences of the war and the degree of identification of these sectors with the political causes at stake during that process. Thus, the reasons why the members of both troops or the summoned militias fought is questioned, as well as the political concepts used in their speeches to identify themselves with the struggle in favor of a given cause and the fees requested to remain in the military corps.

Keywords: War of independence, popular sectors, patriots, royalist army, south-Andean area

\section{Aproximaciones a "lo popular"}

Cuando analizamos el estudio de "lo popular", debemos tener en cuenta que han existido diversas teorías que han intentado acercarse a un concepto y definición de lo popular y, en ocasiones, han persistido confusiones acerca del verdadero significado del vocablo.

El diccionario de la Real Academia Española de 1737 definía el pueblo como "el lugar o ciudad que está poblado de gente, el conjunto de gentes que habitan un lugar" o también, "la gente común y ordinaria de alguna ciudad o población, 
a distinción de los nobles" - la plebe, el vulgo- y popular como "lo que toca o pertenece al pueblo". ${ }^{2}$ Las acepciones de lo popular y del pueblo son diversas de acuerdo con los contextos y se relacionan con la pertenencia e identificación con un lugar determinado, un gobierno ejercido por una amplia mayoría, o bien, se refieren a los sectores más bajos dentro de la escala social. Esta última acepción adquiere una importancia fundamental pues, a pesar de su abierta y ambigua definición, lo popular se refiere, precisamente, a aquellos grupos sociales alejados de los grupos dominantes, de sus vínculos de poder, redes, posiciones y estatus privilegiados.

¿Quiénes conformaban los sectores populares? Ese conjunto incluía a sectores de la ciudad y su ámbito rural que presentaban diferencias étnicas (blancos, ${ }^{3}$ indios, negros, mestizos, mulatos, zambos), ocupacionales (zapateros, carniceros, sastres, artesanos) y jurídicas (esclavos o libres). El elemento unificador de estos grupos como conjunto no se daba únicamente por estas cuestiones, sino por características y experiencias comunes compartidas por sus actores, a las que se agregaban las relaciones establecidas con los sectores dominantes (Davio, 2018, pp. 37-38).

Los sectores populares eran difíciles de delimitar por sus diferentes actividades y características étnicas y sociales. No compartían iguales gustos ni intereses, pues provenían de diferentes mundos sociales. Las élites los concebían como ajenos a sus espacios de poder, pero no a sus vínculos cotidia-

2 Cfr. Diccionario de la lengua castellana, en la que se explica el verdadero sentido de las voces, su naturaleza y calidad, con las phrases o modos de hablar, los proverbios o refranes, y otras cosas convenientes al uso de la lengua (...) Compuesto por la Real Academia Española, Imp. de Francisco de Hierro, t. V. Madrid, 1737.

3 Como los españoles y los nacidos en América, con condiciones sociales y económicas precarias. 
¿Patriotas contra realistas?: Participación y experiencias de los sectores populares durante la guerra en el espacio sur-andino, 1809-1825

nos, dado que convivían cotidianamente con ellos -muchos formaban parte del servicio doméstico- aunque eran considerados diferentes y marginados del círculo de privilegios y formas de vida de las élites y reconocidos como "los otros". Considero que solo podía aglutinar a estos sectores la condición de subordinación que presentaban con respecto a las élites, si bien dicha condición fue modificándose y permitiendo cierta apertura en algunos momentos claves. Además, la mayoría de los sectores populares integraron las tropas de las milicias o el ejército de línea. Este indicador fue compartido por un importante porcentaje de sus integrantes, lo cual permite identificarlos dentro de esos roles en función del proceso de militarización en estudio, además, la composición social de las tropas permite comprender la complejidad de la sociedad y, en particular, de los sectores populares (Davio, 2018, p. 38).

\section{Los sectores populares como integrantes de las tropas realistas y revolucionarias durante la guerra en el espacio sur-andino (1809-1825)}

Desde sus orígenes, el ejército conformado en Buenos Aires se concibió como la plataforma base para llevar la revolución $y$, de ser preciso, la guerra hacia las demás provincias del virreinato. Así, el ejército debió reorganizarse y constituirse en función de diferentes autoridades, que perseguían objetivos, como la obtención de adeptos a la causa, la aprobación de las autoridades provinciales al proceso iniciado en Buenos Aires y la lucha contra el enemigo con la consecuente necesidad de numerosos recursos materiales y humanos.

El Ejército Auxiliar del Perú fue creado en junio de 1810 por decreto de la junta de Buenos Aires para combatir a los realistas en el espacio altoperuano. Partió con compañías de infantería y caballería, bajo el mando de Antonio González Balcarce y de Juan José Castelli en su marcha hacia el norte. 
En el trayecto, fue incorporando gente de diversas provincias hasta su llegada a Tucumán.

Una vez vencido el ejército realista en Tucumán en 1812 y en Salta en 1813, el ejército Auxiliar del Perú sufrió las derrotas en Vilcapugio y Ayohuma -en 1813 y 1814, respectivamente- $y$ finalmente en Sipe en 1815. El peligro en la frontera norte del virreinato pronto planteó un cambio de estrategia para la recuperación espacio altoperuano desde ese frente. ${ }^{4}$

El principal objetivo de ese ejército era la recuperación del territorio de Charcas, ${ }^{5}$ fuente de riqueza económica y cultural. ${ }^{6}$

4 Debido a ese cambio de estrategia de guerra, se decidió implementar la estrategia planteada por San Martín en su campaña de los Andes para recuperar los territorios del Perú y el Alto Perú.

5 Se destaca que también se utiliza el término Alto Perú, según los documentos encontrados en el contexto seleccionado cuando se refieren al territorio de la actual Bolivia y su relación con la guerra contra los revolucionarios del Río de la Plata. Sin embargo, la historiografía boliviana ya ha advertido que la terminología más acorde proveniente de los tiempos coloniales es el territorio de la Real Audiencia de Charcas, denominación que designa a todo el territorio audiencial y no sólo a la su sede, La Plata. Cfr. Barnadas, 1989; Roca, 2017; Revilla Orias, 2009, p. 38.

6 Desde la época colonial, Charcas constituyó una de las regiones más pobladas y ricas, al comprender la importante provincia minera de Potosí y la ciudad de Chuquisaca, la cual contaba con una de las universidades más prestigiosas y donde se formaron algunas personalidades políticas que iban a liderar luego los movimientos revolucionarios en América del Sur. Dicho territorio, perteneciente a la Real Audiencia de Charcas, comprendía la región que hoy ocupa la actual Bolivia y estaba conformado por las cuatro provincias que desde 1776 pasaron a formar parte del virreinato del Río de la Plata. Después de los movimientos de Chuquisaca y la Paz en 1809. y la posterior proclamación de la junta en Buenos Aires en 1810, el virrey del Perú decidió anexionar ese territorio y se convirtió en foco de atención por parte de las autoridades revolucionarias porteńas, preocupadas por su recuperación (Davio, 2017). 
¿Patriotas contra realistas?: Participación y experiencias de los sectores populares durante la guerra en el espacio sur-andino, 1809-1825

Para ello, resultó imprescindible implementar una política basada en el reclutamiento masivo. En los primeros dos ańos de guerra, el gobierno de Buenos Aires pensó que las levas debían estar destinadas a gente sin oficio, a los vagos, a fin de evitar un desorden económico y social en las diferentes regiones afectadas por la guerra. Por ese motivo, comenzaron a aparecer excepciones a tales reclutamientos para los profesionales, los peones en servicio y aquellos que tuvieran un empleo público o tarea útil que cumplir.

En general, los cargos de oficiales estuvieron destinados a españoles americanos, incluso en los cuerpos de color (Halperin Donghi, 1993, p. 203). Para los catalogados como pardos y morenos, grupo integrado por mestizos, mulatos, zambos e indígenas libres, se crearon regimientos en 1812 y 1813. Algunos de ellos tuvieron la posibilidad de ascender dentro del rango militar a títulos honoríficos que implicaban cierto posicionamiento social y mejoras económicas derivadas de los sueldos militares para ellos y sus familias, como también subsidios para enfermos, viudas, inválidos o ciertos privilegios por el hecho de pertenecer a la jerarquía militar, como el goce de fueros.

Son escasos los trabajos que analizan la perspectiva de los "vencidos", pues la historiografía tradicional ha centrado el estudio en los que ganaron la guerra que, desde una concepción nacionalista, buscaba los orígenes de una identidad nacional y centraba el análisis en las rebeliones de fines del siglo XVIII (Hamnett, 2000, p. 4). Otros, se han enfocado en la organización del ejército realista una vez producido el proceso revolucionario en Buenos Aires (Luqui Lagleyze, 1996) y el apoyo de las élites alto y bajo peruanas en su mantenimiento y organización (Vargas Esquerra, 2010, León, 2010; 2004 (No está en las referencias bibliográficas); O”Phelan y Lomné, 2013; O’Phelan, 2014). 
En los últimos años, se han abordado temas diferentes referidos a la política de las autoridades virreinales y jefes del ejército realista, a conflictos surgidos en el seno del mismo que provocarían su desenlace a favor de los revolucionarios (Mazzeo, 2009), a las similitudes entre las estrategias y recursos adoptados entre estos y los jefes revolucionario (Sobrevilla, 2012; Ortemberg, 2011) y a la naturaleza "fidelista" de las tropas dentro de los cuerpos militares, debido a concesiones y retribuciones que habrían actuado como una forma de motivación al seguimiento y sostén de esta causa. ${ }^{7}$

Estos análisis recientes han realizado avances importantes en cuanto a la conformación de ese ejército y a las estrategias y tácticas que debieron asumir sus líderes y seguidores a la hora de ganar adeptos a su causa durante el largo período en que duró la guerra en el territorio latinoamericano. Los estudios dan cuenta de ese proceso y asumen el desafío de estudiar a los actores que lucharon en pos de una causa que ya veía vislumbrar su decadencia, pese a los cambios y modificaciones llevados a cabo para intentar que la población rechace las propuestas revolucionarias de los insurgentes. ${ }^{8}$

El Ejército Real del Perú, que lideró la causa política encargada de defender al rey para lograr la permanencia del dominio colonial en América, comenzó a operar para combatir los movimientos surgidos en mayo y julio de 1809 en Chu-

7 Pueden destacarse los trabajos de Cecilia Méndez sobre las iquichanos realistas en el Perú durante la etapa republicana y los de Marcela Echeverri para el caso los indígenas y esclavos realistas en Popayán, Colombia. Cfr. Méndez, 1991, pp.165-188; Echeverri, 2009, pp. 4572; Echeverri, 2013, p.. 449-467; Ribeiro, 2013; Ferreira, 2016, pp. 41-60; Moreno Gutiérrez, 2014, pp. 1078-1122.

8 Me estoy refiriendo específicamente a la Constitución Liberal de Cádiz de 1812 y sus intentos de implementación en diferentes territorios americanos. 
¿Patriotas contra realistas?: Participación y experiencias de los sectores populares durante la guerra en el espacio sur-andino, 1809-1825

quisaca y La Paz, respectivamente. Una vez sofocados estos, el virrey Fernando de Abascal nombró a José Manuel de Goyeneche general en jefe del ejército y como segundo general a Juan Ramírez. Desde Lima, se decidió una reorganización del ejército, se movilizaron tropas de la capital, Puno, Arequipa y Cuzco y el cierre de las fronteras con el Perú y quedó un ejército de retaguardia en la línea del Desaguadero más un ejército de operaciones al mando de Vicente Nieto y luego, de Juan Ramírez (Luqui Lagleyze, 1996, p. 65).

En esa primera etapa, que se extendió hasta 1813 con el relevo de Goyeneche por el general Joaquín de la Pezuela como general en jefe, dicho ejército estuvo conformado, en su gran mayoría, por milicias indígenas y criollas de diferentes ciudades del Perú, a las que se agregaron algunas tropas de Charcas. Casi no existía tropa veterana.'

Ya he analizado en otro trabajo (Davio, 2019, pp. 307-309) cómo el general Pezuela, desde su asunción al mando en julio de 1813, comenzó a observar el grado de deserción de las filas de los diferentes regimientos. ${ }^{10}$ En sus memorias hace notar la "mala gana" de las tropas que habían ido a Huaqui y que luego de las derrotas sufridas, tanto los “juramentados de Salta" como los paisanos, inducían a los soldados a la deserción (Sobrevilla, 2010).

9 Cfr. Luqui Lagleyze, 1996, p. 56. Pezuela fue quien reorganizó el ejército realista a partir de 1814 y transformó en unidades de línea a las tropas milicianas.

10 En un informe posterior fechado en 1818, ya siendo virrey, Pezuela continuaba advirtiendo la falta de motivación para participar en esta guerra y que (...) "todas las provincias del virreinato, aunque no sean afectan al Rey, aborrecen la larga inquietud de la guerra que padecen". Informe de Pezuela, 13 de noviembre de 1818, Archivo General de Indias (AGI) Sevilla, Estado, 74, (De la Puente Candamo, 2015, p. 174). 
El conflicto bélico entre ambos bandos se desarrolló con mayor intensidad en Charcas $^{11}$ y en las provincias de Salta y Jujuy, que en varias ocasiones fueron ocupadas por las tropas del rey y debieron afrontar el conflicto de forma más próxima. ${ }^{12}$ A partir de 1816, el Ejército Auxiliar del Perú se acantonó en Tucumán como retaguardia y Belgrano se encargó de disciplinar los cuerpos e instruir militarmente a las tropas, pero el conflicto más grave se desarrolló en los espacios anteriormente mencionados, donde la guerra se tornó más cruenta, a causa de la resistencia de buena parte de las autoridades y de los grupos étnicos que comenzaron a participar y entraron en una verdadera pugna de intereses e identificación con una u otra causa por sus propios requerimientos y pactos constituidos desde tiempos coloniales. A ello se sumó el sistema de guerrillas que puso en jaque constante al ejército del rey ${ }^{13}$ mediante ataques esporádicos tendientes a debilitar

11 Para el historiador José Luis Roca (2017, pp. 120-122), el forcejeo entre Charcas y Lima adquirió un nuevo ímpetu desde la instalación de la Audiencia y se extendería durante más de dos siglos en la que la primera estuvo supeditada a la segunda. Persistió así, la controversia en materia de justicia, gobierno y guerra, para ver qué correspondía al virreinato y qué a la Audiencia. Debido a la gran distancia de la sede virreinal y el hecho de controlar la riqueza de Potosí, la Audiencia incursionaba en diversas cuestiones. Eso creaba fricciones permanentes con la audiencia y con el propio virrey de Lima o de Buenos Aires, al crearse la nueva sede virreinal a fines del siglo XVIII.

$12 \mathrm{La}$ experiencia de las invasiones realistas en las provincias de Salta y Jujuy, junto con la guerra de guerrillas liderada por Martín Miguel de Güemes y sus "gauchos infernales" fueron analizadas por Sara Mata, 2002, 2007, 2008.

13 Una vez sofocadas las sublevaciones indígenas a principios de 1812 surgieron los diferentes "caudillos" que lograron mantener un ambiente de insurgencia en la región, a la espera de la llegada del nuevo ejército revolucionario. La actuación de esos líderes, entre 1811 y 1813, permite relacionar este tipo de sublevaciones indígenas previas con la organización de un sistema organizado de guerrillas que consti- 
¿Patriotas contra realistas?: Participación y experiencias de los sectores populares durante la guerra en el espacio sur-andino, 1809-1825

y devastar al enemigo, dejándolo sin hombres, provisiones ni recursos básicos con que abastecerse e impidiendo que las tropas realistas, principalmente durante los años 1814 a 1816 pudieran avanzar y tomar el control del territorio de las Provincias Unidas del Río de la Plata. ${ }^{14}$

Durante el período de reinstalación del absolutismo, Pezuela fue el responsable, al ser designado virrey en 1816, de volver al statu quo anterior a 1808 a fin de lograr una "pacificación realista" en los territorios de la Audiencia de Charcas y la Capitanía General de Chile, esta última sin poder llevarse a cabo, debido a los triunfos de las fuerzas patriotas en Chacabuco y Maipú en 1817 y 1818 (Peralta Ruiz, 1995).

El motín de Aznapuquio de 1821 generó una suerte de golpe de Estado ocasionado por los militares que respondían a De la Serna, logró el derrocamiento de Pezuela y la asunción de

tuyeron a partir de 1814 y hasta fines de 1816 la base de la resistencia insurgente en el Alto Perú frente al ejército virreinal (Soux, 2015, pp. 212-220).

14 En contraposición con lo sostenido por la historiografía tradicional sobre el sistema de guerrillas - al cual prefirió catalogarlas "republiquetas"- los estudios de los últimos años apuntan a considerar esa estrategia de guerra como un sistema sumamente organizado y jerárquico, con un líder a la cabeza, pero subordinado a un gobierno superior, en este caso, al revolucionario de Buenos Aires, a quien prestaron apoyo constante y abrieron el camino a un territorio de tan difícil acceso. Sin embargo, luego de la derrota del ejército de Rondeaú en noviembre de 1815 y la posterior muerte de sus principales líderes entre 1816 y 1817, las guerrillas entraron en decadencia y quedó un único bastión de la insurgencia en el valle de Cochabamba y La Paz (Soux, 2009); véase también Mamani Siñani, 2012, pp. 433-500. Otros estudios antropológicos señalan que existieron varios sistemas de guerrillas vinculados de forma directa con los diferentes ejércitos porteños, incluido el de José de Rondeaú, que intentaron, al igual que las guerrillas realistas, mantener una coordinación estrecha con ambos ejércitos regulares (Nicolas, 2018, p. 128). 
la Serna como virrey. Con la llegada de José de San Martín en 1821 a las costas peruanas y al puerto del Callao y la adhesión cada vez mayor a las tropas e ideales revolucionarios, el nuevo virrey decidió trasladar la capital al Cusco y desde allí continuar la resistencia realista, la cual duró hasta 1824 y abrió paso a la decisión de declarar definitivamente la independencia en 1826 (Sala I Vila, 2011, pp. 693-694).

\section{Experiencias de soldados patriotas y realistas}

La cuestión si las tropas revolucionarias provenientes del Río de la Plata, que llegaron en diferentes momentos al territorio en donde se desarrolló la guerra por la recuperación del espacio altoperuano, se identificaron o no con la causa política, es una problemática que se debate desde hace algunas décadas en la historiografía del espacio sur-andino. ${ }^{15}$

La identidad y los sentidos de pertenencia que se suscitaron a partir de la guerra en los diferentes espacios donde se desplegó el conflicto ha sido un objeto de indagación centrado en la comprensión de los procesos de construcción de identidades desde una noción separada de la idea "homogeneizante", "nacionalizante" y "esencialista", que caracterizó a los estudios historiográficos más tradicionales que señalaban la preexistencia de una nación en el contexto de la revolución y la independencia (Amadori y Di Pasquale, 2014, pp. 1314). ${ }^{16} \mathrm{Al}$ respecto, este trabajo intenta relacionar los sentidos de pertenencia de los sectores populares dentro de un bando

15 Muchos autores han coincidido en que los ejércitos debieron "ganarse" la adhesión de gente para hacer la guerra contra el enemigo (Thibaud, 2005).

16 Los primeros análisis de José Carlos Chiaramonte apuntaron al análisis de las identidades políticas en el contexto de la revolución y la independencia (Chiaramonte, 1997). Véanse también Mata y Bragoni (2007); Chaile y Quiñonez (2017), entre otros. 
¿Patriotas contra realistas?: Participación y experiencias de los sectores populares durante la guerra en el espacio sur-andino, 1809-1825

u otro a fin de hallar referencias que nos puedan proporcionar indicios para el seguimiento de dichas causas políticas, más allá de las adscripciones locales y los sentidos de "patria" asociados al territorio de origen.

Para el caso argentino, algunos estudios señalan cómo los sectores populares, en su mayoría miembros de las tropas, idearon una serie de tácticas y estrategias para expresar sus desavenencias y resistencias, como la petición de derechos y concesiones por su participación militar. ${ }^{17}$

En los Andes meridionales, se han analizado temas relativos a la actuación y "concientización política” de los campesinos y la plebe urbana como integrantes de las tropas de los movimientos guerrilleros y revolucionarios, la participación indígena y popular en los ejércitos y milicias, ${ }^{18}$ y las exhortaciones pronunciadas por los curas rurales. Los trabajos de Julio Siles Salinas, José Luis Roca, María Luisa Soux, Rosana Barragán, Itala de Mamán, Esther Aillón y Roger Mamani Siñani, entre otros, han contribuido a complejizar el estudio de la guerra de Independencia en Charcas, tanto desde la comprensión de la posición particular asumida frente a la fidelidad a la Corona planteada por el virrey de Lima desde los

17 Véanse Di Meglio, 2006; Fradkin, 2008; Mata de López, 2002; 2007; Bragoni, y Mata, 2007; Paz, 2008; Bragoni, 2008; Rabinovich, 2013, Rabinovich, 2017; Di Meglio, 2012; Fradkin y Di Meglio, 2013; Davio, 2018, entre otros.

18 Entre los primeros trabajos que tuvieron en cuenta la participación indígena y mestiza podemos citar a Valencia Vega, 1962 y Arze Aguirre, 1987. En los últimos años, se ha comenzado a prestar mayor interés a la participación de esos sectores sociales y se ha profundizado el análisis y reconocimiento de la repercusión que tuvo la independencia o la lealtad al rey en el espacio charqueño, véanse Rodríguez Ostria, 2012; Torres, Castro Torres, Nicolas, 2013; Peña Hasbún, 2015; Peña Hasbún, 2017; Siles Salinas, 2009; Soux, 2015; Soux, 2013; Aillón Soria, 2010, entre otros. 
sucesos de 1809 y el movimiento revolucionario de Buenos Aires en 1810, ${ }^{19}$ como del análisis de los diferentes grupos sociales participantes en la guerra, según las opciones políticas que siguieron. ${ }^{20}$ En ese sentido, resultan significativos los nuevos estudios sobre la guerra y la revolución en Charcas con sus antecedentes y consecuencias (Soux, 2015).

Teniendo en cuenta las experiencias de las autoridades políticas y militares de la dirigencia revolucionaria, encargadas de armar, disciplinar y exhortar a las tropas de su mando para la defensa de la "patria" y la lucha contra los defensores de la causa del rey, el problema se centra en analizar la recepción de las convocatorias por parte de la tropas para dilucidar si realmente esos cuerpos militares que ocuparon en su mayoría

19 La historiografía boliviana ha realizado un importante aporte sobre los movimientos revolucionarios acontecidos el 25 de mayo de 1809 en Chuquisaca y el 16 de julio del mismo año en La Paz. Los estudios de las últimas décadas señalan su condición revolucionaria y su íntima relación con los reclamos sostenidos en los levantamientos indígenas de 1780 y la crisis monárquica de 1808 , así como también su aporte y continuidad con el proceso que se inició un año después en Buenos Aires, lo que generó la guerra con el bando realista por la recuperación de ese espacio. Sobre la importancia de la revolución de Chuquisaca en 1809 y el posterior levantamiento en La Paz existen importantes estudios que dan cuenta de las dimensiones de dicho proceso, los que fueron renovándose de acuerdo con las demandas historiográficas y políticas de los últimos años, pero dan cuenta de su complejidad y sus proyecciones en todo el espacio sudamericano. Cfr. Abecia y Oropeza, 1895; René Moreno, 1940; Barnadas, 1973; Roca, 2007; Just Lleó, 1994; Barragán, 2012, 2013a, 2013b, Soux,2 2012, 2013, 2015; Mamani Siñani, 2012; Revilla Orias, 2009; Loayza Valda, 2013; Orias Bleichner, 2013, entre otros.

20 Como ya he mencionado, José Luis Roca concibe al territorio de Charcas como un espacio social que construyó un proyecto político diferente del pretendido por el virrey del Perú o los revolucionarios de Buenos Aires, que planeaban usurpar el territorio de acuerdo con sus propios intereses económicos y políticos (Roca, 2017). 
¿Patriotas contra realistas?: Participación y experiencias de los sectores populares durante la guerra en el espacio sur-andino, 1809-1825

los rangos más bajos y eran de composición étnica y espacial muy heterogénea se identificaron con la lucha y la "patria" y de qué manera respondieron a sus propios intereses y expectativas puestos en juego en ese conflicto que duró hasta 1826.

Cabe preguntarnos, entonces, la razón por la que luchaban los integrantes de ambas tropas de los ejércitos o de las milicias convocadas para tal fin, qué tipo de conceptos políticos en sus discursos sobresalen al identificarse con la lucha a favor de una causa determinada y qué retribuciones pedían a cambio para permanecer dentro de la lucha. Estos interrogantes sugieren temas complejos de responder debido a la escasez de fuentes que respalden tales identificaciones, lo que lleva a la necesidad de apelar, metodológicamente, a una complementariedad en la documentación utilizada y a la búsqueda de indicios necesarios para reconocer sus experiencias, ${ }^{21}$ como también el análisis de expedientes judiciales, donde pueden hallarse casos en los que se vieron involucradas las tropas. ${ }^{22}$

Para el caso de las tropas patriotas vinculadas con los movimientos insurgentes en el espacio sur-andino, hemos encontrado experiencias de soldados actuando en el territorio de Charcas, el cual permaneció durante muchos años bajo el control de los realistas, otros que fueron acusados de haberse involucrado con caudillos insurgentes, haber difundido noti-

21 Sobre la lectura atenta a toda clase de indicios, véase Ginzburg, 2002, p. 11.

22 Las fuentes utilizadas fueron recopiladas de diferentes archivos y bibliotecas, colecciones documentales y documentación inédita existente en los archivos históricos de Argentina (Sala X, sumarios militares) y Ejército Auxiliar del Perú (AGN), Bolivia (Fondo Emancipación, Archivo y bibliotecas Nacionales de Bolivia, Sucre) y Perú (Fondo Colonial Archivo General de la Nación y archivos inéditos de la Biblioteca Nacional del Perú). 
cias a favor de esta causa o de actuar como espías para informar sobre los movimientos del ejército contrario. En todos esos casos se iniciaron declaraciones por parte de funcionarios judiciales a fin de averiguar los motivos que llevaron a tales acusaciones. Como resultado de ello, hay algunos datos claves que permiten adentrarnos en el mundo de la guerra y en las experiencias de los actores. Se han encontrado expedientes en donde es posible reconocer a miembros de las tropas, en su mayoría indígenas, acusados de participar a favor de los patriotas. Por ejemplo, en 1811 se acusó a dos indios de Yamparáez y Tarabuco de difundir papeles para asaltar la ciudad de Chuquisaca que, según testigos, "los cholos junto con los habitantes de la localidad, se habían unido para atacar la ciudad. Cuando se le preguntó a uno de los apresados, el mulato Vicente Palacios, natural de Yamparáez, éste afirmó que se le habían hecho cargar cebada para abastecer a la tropa y las mulas de los soldados". ${ }^{23}$

De 1812, hallamos un caso en que los mismos caciques de indios de diferentes jurisdicciones fueron acusados de haber actuado a favor de los "patriotas" y de difundir noticias de esta causa. Los indios, la mayoría del pueblo de la Rinconada en la provincia de Jujuy, habían admitido haber apoyado a los patriotas "pensando que ésa era la justa causa del Rey", pues todos los pueblos vecinos seguían la misma causa. ${ }^{24}$

En otro expediente también de 1812 , se vio implicado en una causa el cacique Manuel Ayaviri, de la localidad de Sacaca, Chayanta, por delitos de infidencia. ${ }^{25}$ Según testigos,

23 Archivo y Biblioteca Nacionales de Bolivia (en adelante, ABNB), Fondo Emancipación (EM.) 65. Diligencias seguidas contra la conspiración y asalto en La Plata.

24 ABNB. EM. 79. Año 1812. Expediente contra los aprehendidos en Suipacha.

25 ABNB. EM. 103. Año 1812. 
¿Patriotas contra realistas?: Participación y experiencias de los sectores populares durante la guerra en el espacio sur-andino, 1809-1825

la mayoría indios bajo su comandancia, el acusado los había obligado por la fuerza a seguirlo y a responder a las órdenes del insurgente Manuel Terrazas, que llegó a reclutar más de 2000 indios en tres oportunidades para combatir contra las armas del rey. Sin embargo, según declaraciones, también les había ofrecido la libertad del tributo, de la mita y obvenciones parroquiales, lo cual probablemente habría constituido una motivación interesante para seguirlo. El cacique, además, fue acusado de matar a uno de sus indios, Manuel Chacmi, por lo que la causa finalmente fue elevada para que el jefe del ejército del rey dispusiera lo que creyera conveniente.

En esos casos elevados a la justicia ordinaria, los miembros de las tropas, en su mayoría indígenas, alegaban no tener relación con la causa patriota o, en todo caso, haber sido obligados a participar por parte de sus propios caciques. Sin embargo, se mencionan datos por los cuales podemos comprobar las motivaciones que los habrían llevado a apoyar la causa, no solo movidos por el reclutamiento forzoso. Además, la intervención en un bando u otro, al menos en la primera etapa de la guerra que se extendió hasta 1813-1814, también ofrecía la oportunidad de intentar una exoneración en la causa judicial, alegando uno de los caciques, haberse confundido al participar como soldado de las tropas patriotas por creer que estas representaban "la justa causa del Rey." ${ }^{26}$

El valioso aporte de las memorias del tambor José Santos Vargas también permite comprender cómo sectores de diversas

26 Recordemos que hasta 1812, los discursos de las autoridades políticas, jefes y oficiales militares revolucionarios seguían sosteniendo en sus proclamas y exhortaciones la defensa de la patria identificada como la defensa sagrada de la causa del rey, hecho prisionero, continuaba ejerciendo sus dominios representado por el gobierno autónomo instaurado en Buenos Aires desde 1810. 
condiciones étnicas y sociales se involucraron ampliamente en la guerra a favor de los patriotas, al describir situaciones en las que ese actor se enroló en dichas tropas involucrándose en las guerrillas lideradas por caudillos a favor de la causa "porteña", como la de Hayopaya. Según su relato, todos en la región se hallaban "contentísimos de estar en servicio de nuestra libertad y estar comprometidos con este sistema [...] esa confianza que siempre triunfaría la libertad de la patria, porque la guerra era nacional y estábamos muy bien informados de que rara o ninguna vez sujetaba el dominante a un pueblo armado por su amada libertad e independencia" (Vargas, 1982, p. 12).

En trabajos anteriores, he sostenido que en los territorios donde también se desarrolló la guerra, como en las actuales provincias del noroeste argentino, los cambios suscitados a partir de la revolución de mayo de 1810 plantearon una nueva experiencia política para los actores. La guerra y la militarización eran recordadas como experiencias caóticas y de constante abastecimiento y contribución a la causa iniciada contra el enemigo. Además, las continuas exigencias de la guerra llevaban al abandono de las labores cotidianas y el sometimiento a una rigurosa disciplina militar destinada al control de las insubordinaciones o desobediencias (Davio, 2018, pp. 186-201).

En cuanto a las identificaciones que los sectores populares adoptaron con la causa perseguida, se puede decir que estas estaban más acordes con el lugar de nacimiento o residencia de ellos o sus familias, con lo cual se identificaban y actuaban en defensa de sus patrimonios. ${ }^{27}$

27 Para Hobsbawm (1994), la pertenencia a algún grupo humano siempre es siempre cuestión de contexto y definición social. 
¿Patriotas contra realistas?: Participación y experiencias de los sectores populares durante la guerra en el espacio sur-andino, 1809-1825

Para Di Meglio, la "patria” conservó durante el siglo XIX la identificación con el lugar de pertenencia u origen de una persona o grupo social, acepción que perduraba desde los tiempos coloniales. A la vez, también fue gestándose una noción de patria con un contenido espacial y social más amplio y una directa referencia sentimental, principalmente desde el proceso revolucionario y la disolución del virreinato del Río de la Plata (Di Meglio, 2008a: 115-129). En ese sentido, la difusión de la liturgia revolucionaria a través de las fiestas cívicas y religiosas y las conmemoraciones públicas adquirieron un papel significativo en la trasmisión de los valores y deberes patrios. Los primeros gobiernos revolucionarios se encargaron de difundir en fiestas y conmemoraciones públicas, la identificación de la causa revolucionaria con la causa de la patria para obtener el apoyo popular (Di Meglio, 2008b, p. 92).

Como ha señalado François Xavier Guerra, las élites intelectuales fueron las encargadas de exaltar los sentimientos e identificaciones con la patria, fundados en las experiencias e historias comunes de toda la población durante las guerras de independencia y la identificación de amplios sectores de la población con una causa más amplia, es decir, por encima de las identidades locales rurales y urbanas (Guerra, 2003).

Esa "patria militarizada" (Fernández Sebastián y Fuentes, 2009, p. 520 No está en las referencias bibliográficas), a la cual se debía defender y estar pronto para combatir en los regimientos y batallones, era usualmente insinuada en las arengas y bandos pronunciados por los jefes militares en los discursos y decretos de las autoridades gubernamentales y en las "exhortaciones" de los intermediarios. De esa forma puede decirse que, en lo concreto, esos sectores pelearon en defensa de sus territorios más cercanos a su lugar de origen y 
de sus bienes o familias ${ }^{28}$, pero también en defensa de un territorio mayor, que podía disgregarse si no tomaban parte en la lucha a la cual eran convocados. Es decir, esa acepción de patria como la causa política que debían defender era conocida y apropiada por los miembros de las tropas. Sin embargo, pudieron identificarse con ella siempre y cuando los sectores dirigentes cumplieran las promesas y concesiones que las tropas consideraban legítimas. Así, las tropas recurrieron a la retórica de la patria toda vez que la consideraron necesaria para la defensa de sus propios intereses y derechos.

Para el caso de los actores que apoyaron por diversos motivos la causa del rey, la mayoría de los documentos escritos por sus seguidores relatan una fuerte adhesión a la causa revolucionaria en Charcas y en el actual territorio de las provincias del noroeste argentino. Esa observación proviene sobre todo de dirigentes, jefes y oficiales identificados con la causa realista, que habían llegado a experimentar la desolación y la falta de motivación por la causa perseguida por parte de las tropas y la población mestiza e indígena. Es decir, esos actores observaban el desgaste provocado por la guerra y la falta de identificación por un bando político por el que "no había interés" por parte de la población o las tropas reclutadas, debido a que no la consideraban propia, como tampoco había manera de convencerlos de que no siguieran apoyando la causa revolucionaria. Al igual que Goyeneche, el posterior general en jefe designado para liderar el ejército real en el Alto Perú, Joaquín de la Pezuela, observaba una resistencia casi generalizada ante las convocatorias, traducida en una amplia adhesión hacia los revolucionarios: "las tres cuartas partes de sus habitantes eran decididos por el sistema de ellos y los ayudaban con extraordinaria voluntad, especialmente los curas y frailes, que son los que más daño han causado a

28 Lo cual explicaría su resistencia a intervenir en territorios considerados ajenos a su jurisdicción. 
¿Patriotas contra realistas?: Participación y experiencias de los sectores populares durante la guerra en el espacio sur-andino, 1809-1825

las armas del Rey, moviendo a sus feligreses en los púlpitos y hasta en los confesonarios a que siguiesen el partido de la independencia”. ${ }^{29}$ Asimismo, uno de los jefes a cargo del ejército en el territorio de Charcas, el comandante Gerónimo Marrón y Lombera, afirmaba al referirse a Cochabamba y alrededores, que "no hay personas leales en este territorio", que los patriotas tenían "todos los caminos libres y francos" y "que la adhesión a los porteños es muy grande". ${ }^{30}$

Las fuentes mencionan algunas motivaciones o concesiones para asegurar el seguimiento a esta causa política en el territorio en cuestión. No obstante, en otros espacios hay evidencias de que los sectores populares participaron activamente como integrantes de las tropas realistas, a consecuencia de las continuas motivaciones y concesiones ofrecidas por miembros de la dirigencia realista del Perú y no así por parte de los patriotas (Echeverri, 2013). Otros estudios rescatan la participación de las tropas en las filas realistas en el espacio de Charcas, con lo cual considero necesario continuar indagando sobre esta cuestión a fin de constatar los discursos de los jefes y oficiales con otros de la propia población involucrada y los sectores sociales más bajos pertenecientes a las tropas, que tenían sus propios intereses políticos y alianzas desde tiempos coloniales. Al seguir a uno u otro bando, los indígenas primero ponían en juego sus propios proyectos po-

29 José Canterac, otro jefe realista, brigadier del Estado Mayor a cargo del ejército del Alto Perú, señalaba también en 1818 las características de esta población, que en su mayoría continuaba adhiriéndose a los revolucionarios, si bien esta lucha por la "patria" -llamada así por los insurgentes- "no es por amor que lo tengan y sí por haber sido seducidos y alucinados por algún cabecilla de opinión". (Colección Documental de la Independencia del Perú, 1971, p. 21) Faltan del autor y volumen).

30 El comandante Lombera a Joaquín de la Pezuela. 16 de julio de 1814. ABNB. Archivo Pezuela. 1.14.1 núm. 00256. 
líticos, centrados en mantener el mayor equilibrio entre el Estado y los ayllus, a fin de garantizar el acceso a la tierra y a sus recursos (Soux, 2009, p. 92).

Las proclamas, convocatorias y exhortaciones emitidas por autoridades, jefes y oficiales militares o intermediarios tenían la intención, al igual que en caso de los revolucionarios, de lograr una verdadera identificación con la causa a la que debían defender. En cuanto a los integrantes de las tropas realistas, apenas se han encontrado casos en los que se vieron implicados individuos que defendían su lealtad al rey o que aparentaban hacerlo con el fin de ser exonerados de los cargos por los que se los acusaba.

En el territorio perteneciente a las provincias actuales del noroeste argentino, donde también se desarrolló la guerra contra los realistas, el general José María Paz relata en sus memorias una anécdota que describe una acción en plena guerra durante la batalla de Salta de 1813, cuando se enfrentó con un soldado que desconocía su adhesión política (Paz, 2000, pp. 38-39). En el enfrentamiento, el oficial apuntando con su puñal exigió a este que le dijera el ejército al cual respondía. Al negarse el soldado, atemorizado, respondió: "al nuestro". Al reiterar su pregunta el oficial, y repetir su respuesta el soldado, el oficial, auxiliado por el capitán Saravia, decidió matarlo. Posteriormente, se le anotició que el soldado pertenecía al ejército realista. Con esa anécdota, es posible ver que la escasez de distintivos que pudieran identificar a los cuerpos militares con un bando político u otro, lo que representaba, tal vez, una posibilidad de salir ileso de una situación embarazosa, ante la imposibilidad de diferenciar al enemigo en el campo de batalla, u optar por el cambio de bando, según las promesas de retribuciones que pudieran ofrecerle y su grado de identificación con el bando que había estado defendiendo. 
¿Patriotas contra realistas?: Participación y experiencias de los sectores populares durante la guerra en el espacio sur-andino, 1809-1825

Para el caso de Charcas, uno de los expedientes judiciales hallados relata el juicio que se inició a un soldado, Don Agustín Ravelo en $1814,{ }^{31}$ quien había arribado desde Buenos Aires en 1809 para sofocar el movimiento juntista surgido en Chuquisaca, e integrado la tropa del mariscal Don Vicente Nieto. ${ }^{32}$ A pesar de haber participado en diferentes batallas y acciones a favor de la causa del rey, de no haberse incorporado -según su testimonio- a las tropas de Castelli una vez arribado este, ni haber dado ningún motivo que pudiera llegar a identificársele como sospechoso o infidente, había sufrido toda clase de calumnias y penurias, por su atributo de "porteño". Con la llegada del general Belgrano había corrido peor suerte, al ser desterrado a Potosí, donde le dieron los epítetos de "sarraceno", sospechoso y "nietista". Luego, había logrado regresar a La Plata una vez que las armas del rey triunfaron en Vilcapugio, si bien se había mantenido notoriamente enfermo hasta ser detenido y apresado nuevamente por considerársele un posible insurgente. La causa finalizó con la petición del acusado del envío de un cirujano que certificara las penurias y enfermedades que había contraído debido a su reclusión. Frente a la constatación de dicho comprobante, Ravelo logró finalmente su libertad y fue exonerado del cargo. Con ese caso, es posible observar de qué manera las identificaciones con la causa asociada a la capital rioplatense, debido al lugar de nacimiento del reo y luego, a la sospecha de su posible seguimiento a los líderes de la revolución, habían llevado a este individuo a ser apresado por las fuerzas del ejército realista y luego a ser rechazado por los propios dirigentes revolucionarios, que también lo tilda-

31 ABNB. Fondo Emancipación, número 207. 1814.

32 Vicente Nieto, como presidente de la Audiencia de Charcas, había enviado a sofocar los movimientos de Chuquisaca y La Paz en 1809 y luego peticionado al virrey del Perú Abascal, que anexione el territorio de Charcas bajo su jurisdicción, a fin de evitar la propagación del movimiento revolucionario surgido en Buenos Aires. 
ron de sospechoso al haber integrado las tropas de Vicente Nieto. Así, imbuido en un clima de constantes cambios e incertidumbres políticas, el soldado no había logrado insertarse dentro de un bando u otro, pese a su supuesta convicción de identificarse y apoyar de manera sostenida la causa del rey.

En otra causa aparece implicado un indio, acusado de participar en el alzamiento insurgente de la doctrina de Andamarca, liderado por el caudillo Peñaranda, en el año $1816 .{ }^{33}$ Según su propia declaración, el indio había asegurado no haber tenido ninguna relación con ese caudillo, sino que, al contrario, uno de sus seguidores había intentado seducirlo diciéndole "que por todos lados estaban batiendo a los realistas", a lo que él le había afirmado que "la patria no servía para nada, que había sido derrotada varias veces" y que, como "indio fiel”, jamás se había mezclado con los insurgentes, y decidió quitarle la vida. Ocho meses después de estar preso por haber efectuado ese homicidio, solicitaba su exoneración, volviendo a reafirmar su identificación con la causa del rey. A pesar de que algunos vecinos españoles y hasta el mismo cacique de su comunidad, habían atestiguado a su favor, la causa continuó sin resolverse hasta 1818, año en que finaliza al menos, el expediente.

De ese juicio, se pueden desprender dos hipótesis: la primera, advierte que la "patria" asociada, como ya hemos afirmado, a la causa revolucionaria, posiblemente constituía para ese indígena la justificación clave para lograr convencer su aparente adhesión a la causa del rey. La segunda, es que la identificación con la causa realista, en plena guerra contra los revolucionarios también era motivo de sospecha, debido quizás a su origen étnico y a la movilización y reclutamiento de indios que realizaban los "patriotas" para recuperar ese espacio des-

33 ABNB. Em. 327. Año 1816. 
¿Patriotas contra realistas?: Participación y experiencias de los sectores populares durante la guerra en el espacio sur-andino, 1809-1825

de $1810 .{ }^{34}$ De esa manera, no estar identificado de manera clara con ningún bando se convertía en una situación embarazosa que, probablemente, podría haber constituido una de las razones de la excesiva demora en la resolución de su causa.

\section{Conclusiones}

De acuerdo con lo analizado, puedo decir que los sectores populares, en su mayoría integrantes de las tropas revolucionarias o realistas involucradas en la guerra en el espacio sur-andino, participaron movidos, en primer término, por las exhortaciones y convocatorias de reclutamiento emitidas por las autoridades políticas y militares de ambos bandos, pero también debido a sus propias motivaciones e intereses que iban más allá de la identificación con un bando político u otro.

Es decir, esos sectores se identificaron con la lucha a favor de una causa, en la medida en que las mismas se correspondieran con sus propias expectativas e intereses puestos en juego. A diferencia de otros espacios mencionados, en el espacio sur-andino desde 1810 se observa en los documentos consultados una fuerte adhesión a la causa revolucionaria iniciada en Buenos Aires y difundida por los principales líderes en

34 Existen estudios que señalan que los realistas habrían reclutado, de la misma manera que los patriotas, a población indígena y mestiza de la región a favor de su lucha política, y remarcan los estragos dejados por el ejército revolucionario en territorio charqueño, que habrían generado la pérdida de seguimiento e identificación con esta causa política (Castro Torres, 2013).

En regiones con fuerte apoyo al bando realista, como en el caso de Potosí, el avance de los indios y mestizos, sus sistemas de guerrillas diseñadas para lograr ver concretados sus proyectos en base a las alternativas políticas vigentes, llevó en ocasiones a miembros de las élites locales a pensar en la posibilidad de pactar una independencia con los revolucionarios, a fin de ver garantizados sus privilegios (Nicolas, 2018, p. 65). 
todo el territorio de las actuales provincias del noroeste argentino y en el territorio de Charcas.

En relación con las convocatorias y exhortaciones de los identificados con la causa revolucionaria, puedo rescatar que dichas exhortaciones y la lucha de las tropas milicianas y de línea asociada a la "patria" permitieron una mayor identificación con ese bando político, a la hora de combatir e identificarse con el conflicto y por los ofrecimientos que los principales líderes hacían a la población para lograr una mayor participación y evitar la deserción masiva.

En cuanto a los seguidores de la causa del rey, se observa que al apelar a la adhesión y seguimiento de esos sectores sociales en el espacio sur-andino, la no utilización del concepto "patria" como símbolo y representación de la guerra habría repercutido negativamente, al menos desde este primer análisis, entre los actores involucrados, como también habrían influido en ello las escasas concesiones y negociaciones establecidas entre los grupos dirigentes y los sectores populares, que habrían tenido una relación directa con el seguimiento a la causa, la deserción y el rechazo a continuar con el sistema colonial, pese a las posibles innovaciones propuestas a partir de la legislación gaditana.

Por último, puedo decir que en ese contexto de constante incertidumbre política que caracterizó al conflicto bélico y que fue definiéndose de acuerdo con diferentes coyunturas temporales en ese amplio espacio a favor de la independencia y luego, a la constitución de nuevos Estados nacionales derivados de la guerra, los sectores populares llegaron a identificarse con uno u otro bando de acuerdo con la gama de posibilidades derivadas del conflicto.

Estar a la expectativa de la resolución del conflicto tiene una amplia relación con los propios proyectos políticos ideados 
¿Patriotas contra realistas?: Participación y experiencias de los sectores populares durante la guerra en el espacio sur-andino, 1809-1825

por esos sectores sociales, como ya han planteado los historiadores. Ello señala la necesidad de continuar indagando en la cuestión, a fin de complejizar el análisis e identificación política con una u otra causa, diseńada por y para las dirigencias políticas pertenecientes a ambos bandos en pugna.

Así, el clima de confusión derivado de la guerra y los conflictos existentes tanto en Europa como en América habría dado lugar a que esos sectores involucrados de forma directa en las batallas buscaran alternativas de supervivencia, más allá de las causas políticas e identificaciones ideadas por los sectores dirigentes. Por ese motivo y de acuerdo con el contexto espacial y temporal, se podía ser "patriota" o "realista", siempre y cuando se vieran reflejadas sus propias expectativas de cambio y posibilidades de mejora en su condición social y jurídica.

Recibido: 26 de octubre del 2020

Aprobado: 20 de abril del 2021

\section{Referencias bibliográficas}

Abecia, V. y Oropeza, S.

(1895). Homenaje al primer grito de independencia dado el 25 de mayo de 1809. Otros documentos históricos. Sucre: Imp. Boliviana.

148 Aillón Soria, E.

(2010) El mulato Francisco Ríos: líder y plebe (25 de mayo 1809- noviembre de 1810). En H. Bonilla (Ed.), Indios, negros y mestizos en la independencia. Bogotá: Universidad Nacional de Colombia, Planeta. https:// doi.org/10.4000/nuevomundo.66996

Albi de la Cuesta, J.

(2009) El último Virrey. Madrid: Olleros y Ramos Eds. 
Amadori, A. y Di Pasquale, M.

(2014) Introducción. Identidades y sentimientos de pertenencia en el espacio rioplatense. Miradas históricas entre la colonia y el período independiente. En A. Amadori y M. Di Pasquale (Coords.), Construcciones identitarias en el Rio de la Plata. Siglos XVIII-XIX. Rosario: Prohistoria.

Arze Aguirre, R.

(1987) Participación popular en la independencia de Bolivia. La Paz: Fundación Cultural Qulpis.

Barnadas, J.

Es muy sencillo: llámenme Charcas. Sobre el problema de los antecedentes coloniales de Bolivia y su histórica denominación. La Paz: Juventud.

Barragán, R.

(2013a) Legitimidades en entredicho: múltiples disputas en Charcas en 1790-95 y 1809-10. Revista Historia y Cultura (37), 49-72.

Barragán, R.

(2013b) La tea de la revolución. La construcción política del enemigo en Charcas. 1809-1810. En S. O'Phelan y G. Lomné, Abascal y la contra-independencia en América del Sur (pp. 227-270). Lima: Fondo Ed. Pontificia Universidad Católica del Perú.

Barragán, R., Soux, M., Seoane, A. M., Mendieta, P., Asebey, R. y Mamani Siñani, R. (Eds.)

(2012)

Reescrituras de la independencia. Actores y territorios en tensión, La Paz, Bolivia. La Paz: Coordinadora de Historia, Plural Eds., Academia Boliviana de Historia.

Bragoni, B.

(2008) Esclavos, libertos y soldados: La cultura política plebeya en Cuyo durante la revolución. En R. Fradkin, ¿Y el pueblo dónde está? Contribuciones para una historia popular de la revolución de independencia (pp.107150). Buenos Aires: Prometeo. 
¿Patriotas contra realistas?: Participación y experiencias de los sectores populares durante la guerra en el espacio sur-andino, 1809-1825

Bragoni, B. y Mata, S.

(2007) Militarización e identidades políticas en la revolución rioplatense. Anuario de Estudios Americanos, 64 (I), 221-256.

Castro Torres, $\mathrm{M}$.

(2013) La visión de los olvidados: la presencia del segundo Ejército Auxiliar rioplatense en Charcas desde la óptica realista. En N. B. Torres, M. Castro Torres y V. Nicolas, 1813. Belgrano en el Alto Perú (pp. 71-99). Sucre: Ciencia Eds.

Chaile, T. y Quiñonez, M.

(2017) Construcciones identitarias y sentidos de pertenencia en el espacio sur-andino al terminar la guerra de independencia. Anuario de Estudios Americanos, 74 (2), 577-588.

Chiaramonte, J. C.

(1997) Ciudades, provincias, estados. Origenes de la nación Argentina, 1800-1846. Buenos Aires: Ariel. Biblioteca del Pensamiento Argentino.

Davio, M.

(2017) Construir la revolución desde la opinión: proclamas, bandos y exhortaciones durante la guerra en el Alto Perú (1810-1814), Nuevo Mundo Mundos Nuevos, Debates, 2017, Recuperado de http://nuevomundo. revues. org/71268.

150 (2018)

Morir por la patria. Participación y militarización de los sectores populares en Tucumán. 1812-1854. Rosario: Prohistoria.

Davio, M.

(2019) Discursos de los (con)vencidos. Abascal, Pezuela y De la Serna frente a la guerra en Charcas (18091825). Revista del Instituto Riva Agüero, 4(1), 285336. Recuperado de https://doi.org/10.18800/revistaira.201901.007 
Di Meglio, G.

(2006) ¡Viva el bajo pueblo! La plebe urbana de Buenos Aires y la política entre la Revolución de Mayo y el rosismo, Buenos Aires: Prometeo.

Di Meglio, G.

(2008a) Patria. En N. Goldman, (Ed.), Lenguaje y revolución (pp. 115-129). Rosario: Prohistoria.

Di Meglio, G.

(2008b) Las palabras de Manul. La plebe porteña y la política en los años revolucionarios En R. Fradkin, ¿Y el pueblo dónde está? Contribuciones para una historia politica popular de la Revolución de Independencia en el Rio de la Plata (pp. 67-106). Buenos Aires: Prometeo.

Di Meglio, G.

(2012) Historia de las clases populares en la Argentina. Desde 1516 hasta 1880. Buenos Aires: Sudamericana.

Echeverri, $\mathrm{M}$. (2009)

Los derechos de indios y esclavos realistas y la transformación política en Popayán, Nueva Granada. 18081820. Revista de Indias, LXIX (246), 45-72.

Echeverri, M.

Abascal, Cádiz y el realismo popular en Popayán. En S. O'Phelan y G. Lomné, Abascal y la contra-independencia en América del Sur (pp. 449-467). Lima: Fondo Ed. PUCP.

Ferreira, P.

(2016) La guerra de independencia española, los "empecinados" y el Montevideo leal. 1808-1814. Pasado Abierto, Revista del CEHis (4), 41-60. Recuperado de http:// fh.mdp.edu.ar/revistas/index.php/pasadoabierto

Fradkin, R. y Di Meglio, G. (Comps.).

(2013) Hacer politica. La participación popular en el siglo XIX rioplatense. Buenos Aires: Prometeo. 
¿Patriotas contra realistas?: Participación y experiencias de los sectores populares durante la guerra en el espacio sur-andino, 1809-1825

Ginzburg, C.

(2002) El queso y los gusanos. El cosmos según un molinero del siglo XVI. Buenos Aires: Crítica.

Guerra, F. X.

(2003) Las mutaciones de la identidad política en la América Hispana. En A. Aninno, Von Dusek y F. X. Guerra (Coords.) Inventando la nación: Iberoamérica en el siglo XIX (pp. 185-220). México: FCE.

Halperin Donghi, T.

(1993) Revolución y guerra. Formación de una élite dirigente en la Argentina criolla. Buenos Aires: Paidós.

Hamnett, B.

(2000) La politica contrarrevolucionaria del Virrey Abascal. Lima: Instituto de Estudios Peruanos.

Hobsbawm, E.

(1994) Identidad. RIFP, 3, 5-17.

Just Lleó, E.

Comienzo de la independencia en el Alto Perú. Los sucesos de Chuquisaca. Madrid: Universidad Complutense de Madrid.

Loayza Valda, J.

(2013) La revolución en Charcas y la Universidad Mayor, Real y Pontifica de San Francisco Xavier en Chuquisaca. Importancia de la intelectualidad platense en la realización de la revolución americana. Memoria del Coloquio. El Pensamiento Universitario de Charcas y el 25 de mayo de 1809 y 1810 (pp. 43-56). Sucre: Ediciones Archivo y Bibliotecas Nacionales de Bolivia.

Luqui Lagleyze, J.

(1996) Historia y campañas del ejército realista (t. I). Buenos Aires: Instituto Nacional Sanmartiniano, Fundación Mater Dei. 
Mamani Siñani, R.

(2012) Visiones y revisiones: los indígenas, el caudillo y la guerrilla en la guerra de independencia. En R. Barragán, M. L. Soux, A. M. Seoane, P. Mendieta, R. Asebey y R. Mamani Siñani, Reescrituras de la independencia. Actores y territorios en tensión (pp. 433500). La Paz: Coordinadora de Historia, Plural Eds., Academia Nacional Boliviana.

Mata de López, S.

(2002) La guerra de independencia en Salta y la emergencia de nuevas relaciones de poder. Andes (13), 177-188. Recuperado de https://www.redalyc.org/articulo. oa? id $=12701305$

Mata, S.

(2007) Los gauchos de Güemes. Buenos Aires: Eudeba.

Mata, S.

(2008) Insurrección e independencia: la provincia de Salta y los Andes del Sur. En R. Fradkin (Ed.). ¿Y el pueblo dónde está? Contribuciones para una historia política popular de la Revolución de Independencia en el Río de la Plata (pp. 177-208). Buenos Aires: Prometeo.

Mata, S. y Bragoni, B.

(2007) Militarización e identidades políticas en la revolución rioplatense. Anuario de Estudios Americanos, 65, 221-256.

Mazzeo, C. (2000)

Las vicisitudes de la guerra de independencia en el Perú, 1817-1824 (pp. 105-136). Lima: PUCP. Cuadernos de Investigación, I.

Mazzeo, C.

(2005) El miedo a la revolución de independencia en el Perú. 1818-1824. En C. Rosas Lauro (Ed.), El miedo en el Perú, siglos XVI al XX (pp. 167-182). Lima: PUCP. 
¿Patriotas contra realistas?: Participación y experiencias de los sectores populares durante la guerra en el espacio sur-andino, 1809-1825

Mazzeo, C.

(2009) Los nudos de la desunión: conflictos y divergencias en la dirigencia del ejército realista durante la emancipación del Perú, 1810-1824. Revista de Indias (247), 105-135.

Méndez, C.

(1991) Los campesinos, la independencia y la iniciación de la República. El caso de los iquichanos realistas: Ayacucho, 1815-1818. En H. Urbano (Comp.) y M. Lauer (Ed.). Poder y violencia en los Andes (pp. 165188). Cusco: Centro Bartolomé de Las Casas.

Moreno Gutiérrez, R.

(2014) Los realistas: historiografía, semántica y milicia. Historia Mexicana, LXVI(3), 1078-1122.

Nicolas, V.

(2018) Betanzos. Cerros, caminos, tambos, haciendas y rebeliones. La Paz: Plural.

Orias Bleichner, A.

(2013) Los seductores mensajeros de Chuquisaca en Buenos Aires. El movimiento de ideas en Chuquisaca y su efecto en la independencia del Río de la Plata. En Memoria del Coloquio. El Pensamiento Universitario de Charcas y el 25 de mayo de 1809 y 1810 (pp. 205240). Sucre: Ediciones Archivo y Bibliotecas Nacionales de Bolivia.

154 O'Phelan, S.

(2014) La independencia en los Andes. Una historia conectada. Lima: Fondo Ed. del Congreso del Perú.

O’Phelan, S. y Lomné, G.

(2013) Abascal y la contra-independencia en América del Sur. Lima: Fondo Ed. PUCP. 
Ortemberg, P.

(2012) Vírgenes generalas. Acción guerrera y práctica religiosa en las campañas del Alto Perú y el Río de la Plata (1810-1818). Boletín del Instituto de Historia Argentina y Americana Dr. Emilio Ravignani, (35/36), 11-42.

Ortemberg, P. y Sobrevilla, N. (Eds.)

(2011) Compendio de los sucesos ocurridos en el Ejército del Perú y sus provincias (1813-1816) de Joaquin de la Pezuela. Santiago: Centro de Estudios Bicentenario.

Paz, G.

(2008) Reordenando la campaña: La restauración del orden en Salta y Jujuy, 1822-1825. En R. Fradkin, ¿Y el pueblo dónde está? Contribuciones para una historia politica popular de la Revolución de Independencia en el Rio de la Plata (pp. 209-222). Buenos Aires: Prometeo.

Peña Hasbún, P. (Ed.).

(2015) La guerra de independencia en Santa Cruz de la Sierra. Según sus historiadores. Santa Cruz de la Sierra: Biblioteca del Museo de Historia.

Peña Hasbún, P.

(2017) Santa Cruz en la guerra de independencia. Nuevas aproximaciones. Santa Cruz de la Sierra: Biblioteca del Museo de Historia.

Peralta Ruiz, V.

(2005) De absolutistas a constitucionales. Política y cultura en el gobierno del virrey Pezuela. Perú 1816-1820. En J. Rodríguez (Coord.), Revolución, independencia y las nuevas naciones de América (pp. 485-501). Madrid: Mapfre Tavera.

Puente Candamo. J. A. de la

(2015) Entre la fidelidad y la ruptura. En C. Contreras y L. M. Glave (Eds.), La independencia del Perú. ¿Concedida, conseguida, concebida? Lima: Instituto de Estudios Peruanos. 
¿Patriotas contra realistas?: Participación y experiencias de los sectores populares durante la guerra en el espacio sur-andino, 1809-1825

Rabinovich, A.

(2013) Ser soldado en las guerras de Independencia. Buenos Aires: Sudamericana.

Rabinovich, A.

(2017) Anatomía del pánico. La batalla de Huaqui o la derrota de la Revolución (1811). Buenos Aires: Sudamericana.

René Moreno, G.

(1940) Últimos días coloniales en el Alto Perú. La Paz: Biblioteca Boliviana.

Revilla Orias, P. (2009). La autonomía revolucionaria de la Real Audiencia de Charcas hacia 1809: cimientos de un Estado independiente. Sucre: Casa de la Libertad, Fundación Cultural Banco Central de Bolivia.

Ribeiro, A.

(2013) Los muy fieles. Leales a la corona en el proceso revolucionario rioplatense. Montevideo/Asunción. 1810-1820. Montevideo: Planeta.

Roca, J. L.

(2017) Ni con Lima ni con Buenos Aires. La formación del Estado Nacional en Charcas. La Paz: Plural.

Rodríguez Ostria, G.

(2012) Morir matando. Poder, guerra e insurrección en Cochabamba. 1781-1812. Santa Cruz de la Sierra: Ed. El País.

156 Sala I Vila, N.

(2011). El trienio liberal en el virreinato peruano. Los ayuntamientos constitucionales en Arequipa, Cusco y Huamanga, 1820-1824. Revista de Indias, LXXI (253), 693-728. 
Sobrevilla, N.

(2010) Hermanos, compañeros y amigos de sus mismos contrarios. Las guerras de independencia en el surandino. 1805-1825. En Dossier: Las guerras frente a la crisis del orden colonial. Hispanoamérica. Buenos Aires, Programa Buenos Aires de Historia Política del Siglo XX. Recuperado de http://historiapolitica. com/datos/biblioteca/sobrevilla.pdf

Soux, M. L.

(2009) Insurgencia y alianza: estrategias de la participación indígena en el proceso de independencia en Charcas. 1809-1812. En Historia y Cultura. Congresos Conmemorativos del Bicentenario de 1809 (34). La Paz: Sociedad Boliviana de Historia.

Soux, M. L. (2013)

Legalidad, legitimidad, lealtad. Apuntes sobre la compleja posición política en Charcas (1808-1811). En V. Hebrard, y G. Verdó (Eds.), Las independencias iberoamericanas. Un objeto de la Historia. Madrid: Casa de Velásquez.

Soux, M. L. (2015)

(Coord.). Bolivia su historia. Reformas, rebeliones e independencia, 1700-1825 (t. III). La Paz: Coordinadora de Historia.

Thibaud, C.

(2005) Formas de guerra y mutación del ejército durante la guerra de independencia en Colombia y Venezuela. En J. Rodríguez (Coord.), Revolución, independencia y las nuevas naciones en América. Madrid: Fundación Mapfre Tavera.

Valencia Vega, A.

(1962) El indio en la independencia. La Paz: Biblioteca Boliviana de Estudios Contemporáneos. 
¿Patriotas contra realistas?: Participación y experiencias de los sectores populares durante la guerra en el espacio sur-andino, 1809-1825

Vargas Esquerra, J. I.

(2004) Cuando no había rey, Abascal lo era de América. Tiempos de América (11), 15-26.

Vargas Esquerra, J. I.

(2010) Goyeneche, un americano al servicio del rey en el Alto Perú.Naveg@mérica. Revista electrónica de la Asociación Española de Americanistas (4). (Recuperado de https://www.academia.edu/2341752/Goyeneche_un_americano_al_servicio_del_rey_en_el_ Alto_Per\%C3\%BA_1808-1813.

Vargas Esquerra, J. I.

(2010) Un hombre contra un continente. José Abascal, rey de América, 1806-1816. León: Akron. 